\title{
Designing and Psychometrics of a Questionnaire to Access the Skills of Health-Workers in Providing Self-Care Program for Pre-diabetic Individuals by PRECEDE-PROCEED Model
}

\author{
Mahmoud Ghasemi \\ Tarbiat Modares University \\ Fazlollah Ghofranipour \\ Tarbiat Modares University \\ Hasan Shahbazi ( $\sim$ h.shahbazi@modares.ac.ir) \\ Tarbiat Modares University \\ Farkhondeh Aminshokravi \\ Tarbiat Modares University
}

\section{Research Article}

Keywords: Psychometrics, Health-workers, Empowerment, Self-care, Pre-diabetes

Posted Date: December 15th, 2020

DOl: https://doi.org/10.21203/rs.3.rs-122794/v1

License: () (1) This work is licensed under a Creative Commons Attribution 4.0 International License.

Read Full License 


\title{
Designing and Psychometrics of a Questionnaire to Access the Skills of Health-Workers in Providing Self-Care Program for Pre-diabetic Individuals by PRECEDE-PROCEED Model \\ Mahmoud Ghasemi ${ }^{\text {a }}$, Fazlollah Ghofranipour ${ }^{\text {a }}$, Hasan Shahbazi ${ }^{\text {a,* }}$, Farkhondeh Aminshokravi ${ }^{\text {a }}$ \\ ${ }^{a}$ Department of Health Education \& Health Promotion, Faculty of Medical Sciences, Tarbiat Modares University, Tehran, Iran
}

Corresponding author at: Department of Health Education \& Health Promotion, Faculty of Medical Sciences, Tarbiat Modares University, Tehran, Iran.

Fax: +98 (2182884555)

Tel: +98 (2182884868)

Postal code: $14115-111$

E-mail address: H.shahbazi@ modares.ac.ir (H shahbazi)

\begin{abstract}
Aims. - This research aimed at designing and psychometric properties of a questionnaire for health-worker skills evaluation to obtain a self-care program for pre-diabetic patients.

Materials. - The questionnaire items were first developed, utilizing reliable and specialized sources involving papers and scientific books and interviews with experts and specialists in diabetes and health education. The questionnaire's psychometric properties were evaluated utilizing face validity, content validity, construct validity, internal consistency, and stability.

Results. - Due to the results of investigating the texts and interviews, the initial questionnaire, including 54 phrases, was presented. In the face validity section, eight expressions were removed quantitatively. Then, in identifying content validity, three other words were deleted, and the questionnaire was reduced to 43 phrases in general. This questionnaire's exploratory factor analysis revealed four factors involving self-efficacy, attitude, reinforcing factors, and enabling factors. These four factors explained $57.51 \%$ of the total variance of the test. The results of the confirmatory factor analysis also confirmed the factors of the PRECEDEPROCEED model. Cronbach's alpha and intra-cluster correlation index for questionnaire structures ranged from $0.87-0.88$ and $0.87-0.88$, respectively.

Conclusion. - The designed questionnaire has good validity and reliability. It can be said that this questionnaire is a suitable and usable tool for prediabetes in similar research to evaluate health worker skills in obtaining a self-care program for prediabetes.
\end{abstract}

Keywords: Psychometrics, Health-workers, Empowerment, Self-care, Pre-diabetes 


\section{Introduction}

Concerns about non-communicable diseases are among the severe global problems that will cause many issues in these years and the future [1]. Type 2 diabetes is one of the four most significant non-communicable diseases along with cardiovascular diseases, cancers, and chronic respiratory diseases, which together account for $63 \%$ of deaths related to non-communicable diseases in the world [2]. Due to the latest reports from the International Diabetes Federation, there are 425 million diabetics in the world, the number of which will rise to 629 million by 2045, and due to the report, the number of patients in Iran is 5 million, which will increase by nearly 10 million by 2045 [3].

Some predictors of prediabetes, such as age and family history of diabetes, cannot be inhibited. Still, authorities, policymakers, and planners should consider other efficient and preventable factors in prediabetes. Bodyweight in both sexes, waist circumference in women, fasting blood sugar, and two hours after meals and triglyceride and HDL cholesterol concentrations can be controlled by extensive public education programs for healthy nutrition and increased physical activity. Cessation of smoking and increasing literacy levels are other essential factors to decrease prediabetes incidence [4-7].

The global prevalence of prediabetes due to IGT (Impaired Glucose Tolerance) level in 2017 was $7.3 \%$ in the adult population (79-20 years), equivalent to 352.1 million people. In general, the highest prevalence was reported in North America and Caribbean (15.4\%), Central and South America (10\%), and the lowest prevalence was reported in Southeast Asia (3\%) and Europe $(5.5 \%)$ [8].

The incidence rate of prediabetes in Tehran society, after nine years of follow-up of about 6,000 men and women aged 20 years and over healthy in Tehran, 46 men and 38 women out of every 1,000 people developed prediabetes. It means that each year, $4 \%$ of Tehran's total adult population is converted from healthy blood sugar to prediabetes, and this finding is very shocking and alarming [9].

One of the methods to inhibit and control diabetes is self-care behavior. Self-care is defined as a strategy to adapt to life's problems and issues which promote health. Many researchers have indicated that utilizing lifestyle modification and using self-care principles can delay or even prevent diabetes in prediabetes so that behavioral changes alone can decrease the risk of diabetes by 40 to $70 \%$ [10-16].

For patients and prediabetes to deal with diabetes issues, having awareness, knowledge, skills, abilities, and motivations for self-care behaviors requires that health care workers and the health team play a significant role in educating these issues [17, 18].

Today, education is one of the most important ways to control non-communicable diseases, and studies show that with proper education, the complications of non-communicable diseases can be reduced [18]. The use of appropriate educational methods and models empowers health workers to provide optimal health programs [19]. The results of many studies show that in order to improve the quality of health care, the educational skills of health workers should be increased; Also, the growth of the vulnerable population, the change in the view of health from the individual to the community, and the change in the overall health goals from treatment to prevention have led to the provision of primary care and disease prevention by health officials. In this regard, the existence of an appropriate and standard tool that can examine the educational skills of health workers and lead to savings in time and cost of conducting research studies is felt [20-23].

Considering first the increasing prevalence of diabetes and the importance of self-care in controlling diabetes progression in prediabetes, and second the efficient and undeniable role of health workers [24], the current study aimed at designing and psychometric properties of a questionnaire for health-worker skills evaluation to obtain a self-care program for prediabetes of Mazandaran Province, Iran. 


\section{Methods}

The current research is a cross-sectional descriptive-analytical study conducted from January to September 2020. The statistical population of the research was all health workers in Mazandaran province who were able to evaluate the validity and reliability of health workers' skills in obtaining self-care program for prediabetes utilizing the formula

$n=\frac{\left(z_{1-\frac{\alpha}{2}}\right)^{2} p(1-p)}{d^{2}}$

Considering $\mathrm{p}=0.5, \alpha=0.05$, and an error value of 0.05 , a confidence interval of $95 \%$, and considering a $10 \%$ fall, 400 health workers of Mazandaran province were enrolled in the research. The subjects were chosen by random cluster sampling proportional to the size and entered the research. The sampling method was that each of the city's health centers was chosen as a cluster, and the subjects were randomly chosen from each class due to the number of health worker populations in each city. After determining each city's share, the subjects were chosen to utilize random numbers table due to the list of names in the county's health center.

In the first step, valid and specialized resources, including databases (PubMed, Proquest, etc.) papers and scientific books (more than 50 papers, two treatises, and two books), were surveyed. Since no specific comprehensive and standard questionnaire was found for this subject, the questionnaire items (75 items) were designed by interviewing experts and specialists in diabetes and health education and re-examining the most relevant and comprehensive texts and papers.

In the second step, the research team examined the extracted expressions, and the expressions with overlapping concepts were merged, and the initial questionnaire expressions were reduced to 54 phrases. The questionnaire has three parts:

1. Demographic information;

2. Surveying the awareness and knowledge of health workers; and

3. Behavioral and environmental factors (predisposing, enabling, and reinforcing factors) improved health workers' skills in obtaining self-care educational programs for prediabetes patients.

In the third step, two methods of face validity, content validity, and construct validity were applied to identify the questionnaire's validity. To identify the face validity in the qualitative section, we asked 15 health workers to assess each item for "ambiguity", "relevancy", and "difficulty". For the quantitative approach, the same health workers were asked to evaluate the questionnaire and score each item's importance on a 5-point Likert scale to calculate each item's impact score. It was calculated as multiplying the importance of an item with its frequency $($ Impact Score $=$ Frequency $(\%) \times$ Importance $)$. The impact score of 1.5 or above was considered satisfactory as recommended $[25,26]$.

Two qualitative and quantitative methods were applied to identify the content validity of the designed questionnaire; for the qualitative method, an expert panel consisting of 5 health education and health promotion experts, three diabetes experts, and two general practitioners. At this step, the questionnaire was evaluated for 'grammar', 'wording', 'item allocation', and 'scaling' indices. The content validity ratio (CVR) and content validity index (CVI) was calculated using the quantitative method. To identify the content validity ratio, experts will consider each item's necessity, and CVR values higher than 0.62 were accepted due to the Lawshe table. To identify the content validity index (CVI), the criteria for relevancy, clarity, and simplicity of each item were surveyed, and values higher than 0.79 were accepted [25-27].

Exploratory factor analysis and confirmatory factor analysis were applied to identify construct validity, so in this research, due to 43 items of the questionnaire, 200 health workers for exploratory factor analysis and 200 health workers were chosen for confirmatory factor analysis. To investigate the feasibility of exploratory factor analysis (principal component analysis), KMO (Kaiser-Meyer-Olkin) test was utilized for sample size adequacy, and Bartlett's Test of Sphericity was used to assess the appropriateness of the data. The recommended value of KMO for doing factor analysis on data is between zero and 1. KMO values between 0.5 and 0.7 showed moderate factor analysis, 0.7 to 0.8 balanced factor analysis, 0.8 to 0.9 of optimal 
factor analysis, and greater than 0.9 excellent factor analysis [28-30]. Exploratory factor analysis was performed utilizing SPSS software using 200 questionnaires applying principal components with Varimax rotation. To evaluate the structure of factors derived from the exploratory factor analysis, it must fit the confirmatory factor analysis model. To perform confirmatory factor analysis with data from 200 questionnaires to investigate the suggested factor structure, all sub-branches' internal reliability and correlation among sub-things were performed. Several indicators must be considered to identify a model's fitness, and first, the chisquare index is investigated. Since the chi-square value is commonly very high and significant in high volume samples, it is not a good indicator for identifying the model's fitness. It is better to examine the $\chi^{2} / \mathrm{DF}$ index, a ratio of Chi-square to the degree of model freedom. For this index, values 1 to 5 are appropriate for fitting the model. Some of the indicators applied in this research were comparative fit index (CFI), the goodness of fit index (GFI), root mean square error of approximation (RMSEA), chi-square index $\left(\chi^{2}\right)$, and its corresponding degree of freedom. Moreover, the adjusted goodness of fit index (AGFI) was that the acceptable values for RMSEA were less than 0.1, and for CFI, GFI, and AGFI between 0 and 1, the closer to 1, they have more excellent fitness [25, 31-33].

Internal consistency was measured utilizing Cronbach's alpha coefficient on a group of 30 health workers with a work experience of at least ten years. Cronbach's alpha was equal to or greater than 0.7 was considered appropriate [34-36]. Stability evaluation was handled through the test-retest method. The significant point in this method is the time interval between the two tests. The researchers have suggested this interval of two weeks to a month. They completed the instrument within two weeks and then compared the scores obtained in two steps applying the Pearson correlation coefficient and intra-cluster correlation index [25]. Ethical approval for this study was obtained from National Institute for Medical Research Development (NIMAD) of the Islamic Republic of Iran (IR.NIMAD.REC.1398.244).

\section{Results}

Participants' mean age was $34.13 \pm 8.94$ years, from which $37.5 \%$ were male, and $62.5 \%$ were female. Other findings of the research are listed in the demographic information section in Table 1. In surveying the face validity in the effect stage of the item with the criterion of $1.5,8$ questions were deleted from the knowledge section and in the next step, in the content validity ratio due to the number of experts and the criterion (0.62) of Lawshe table, and three questions were removed from the reinforcing construct. In contrast, in the content validity index, the question was not deleted due to the criterion 0.79 .

Table 1) Demographic Characteristics of Participants

\begin{tabular}{|c|c|c|}
\hline Variable & Number & Percentage \\
\hline \multicolumn{3}{|c|}{ Gender } \\
\hline Male & 150 & 37.5 \\
\hline Female & 250 & 62.5 \\
\hline \multicolumn{2}{|c|}{ Education } \\
\hline Middle school degree & 34 & 8.5 \\
\hline Diploma & 194 & 48.5 \\
\hline Associate degree & 81 & 20.2 \\
\hline BA and over Marital status & 22.8 \\
\hline \multicolumn{2}{|c|}{91} & 25.2 \\
\hline Single & 101 & 71.2 \\
\hline Married & 285 & 2.8 \\
\hline Divorced & 3 & 0.8 \\
\hline Widow & 11 & 38.5 \\
\hline \multicolumn{2}{|c|}{ Work Experience } \\
\hline 5 to 10 years & 69 & 17.2 \\
\hline 10 to 15 years & 81 & 20.2 \\
\hline
\end{tabular}




\begin{tabular}{|c|c|c|}
\hline 15 to 20 years & 96 & 24.1 \\
\hline \multicolumn{3}{|c|}{ Employment Type } \\
\hline Official & 191 & 47.8 \\
\hline Contractual & 33 & 8.2 \\
\hline Conventional & 176 & 44 \\
\hline \multicolumn{3}{|c|}{ Having a second job } \\
\hline Yes & 36 & 9 \\
\hline No & 364 & 91 \\
\hline
\end{tabular}

Furthermore, 43 questions out of 54 questions, with suitable content validity and face validity, entered the questionnaire's reliability applying Cronbach's alpha, Pearson correlation coefficient, and intra-cluster correlation index. Cronbach's alpha coefficients for the questionnaire structures were 0.87-0.88. A Test-retest test was used to evaluate the consistency of the questionnaire. In this method, the Pearson correlation coefficient was computed among the questionnaire's scores twice in a two-week interval. The interclass correlation coefficient is the most acceptable test for identifying the reliability test. If this index is above 0.75 , stability is desirable (Table 2).

Table 2) Reliability results of the questionnaire

\begin{tabular}{|c|c|c|c|c|}
\hline $\begin{array}{c}\text { Dimensions of the } \\
\text { Questionnaire }\end{array}$ & $\begin{array}{c}\text { Number of } \\
\text { Question }\end{array}$ & $\begin{array}{c}\text { Cronbach } \\
\text { Alpha }\end{array}$ & Correlation coefficient & ICC \\
\hline Predisposing & 9 & 0.88 & 0.84 & 0.88 \\
\hline Reinforcing & 7 & 0.87 & 0.81 & 0.87 \\
\hline Enabling & 9 & 0.88 & 0.78 & 0.88 \\
\hline
\end{tabular}

In the next step, construct validity was assessed utilizing exploratory factor analysis, and the principal components method was handled on 25 items. The computed KMO value was 0.901, revealing the adequacy of the chosen sample for factor analysis, and Bartletts' test was significant at the level of 0.001 , which indicated that the implementation of factor analysis due to correlation matrix in the sample was justified and indicated that there were detectable relationships among the variables that were analyzed (Table 3).

Table 3) Factor Analysis: KMO Sample Adequacy Index and Bartlett Test Results

\begin{tabular}{|c|c|c|}
\hline \multicolumn{2}{|c|}{ Statistics KMO } & 0.937 \\
\hline \multirow{4}{*}{ Bartlett Test } & $\begin{array}{c}\text { Chi-squared } \\
\text { Approximation }\end{array}$ & 4.723 \\
\cline { 2 - 3 } & Freedom Degree & 300 \\
\cline { 2 - 3 } & p-value & 0.000 \\
\hline
\end{tabular}

The first factor described $36.909 \%$ of the common variance (self-efficacy), $10.047 \%$ by the second factor (attitude), $6.392 \%$ by the third factor (reinforcing), and $4.168 \%$ by the fourth factor (enabling). Some items with different loads were placed in several factors. Although it was tried to place the items in factors with the highest factor load, items such as items no. 5 and 6 of the enabling structure were transferred to the lower factor load because it was not compatible with the factor with the highest factor load. All items were loaded in the extracted agents, and at this stage, no items were removed (Table 4).

Table 4) Matrix of rotated factors with varimax rotation and factor load rates of items in each factor

\begin{tabular}{|c|c|c|c|c|}
\hline Item No & Self-efficiency & Attitude & Reinforcing & Enabling \\
\hline 1 & 0.599 & & & \\
\hline 2 & 0.753 & & & \\
\hline 3 & 0.736 & & & \\
\hline 4 & 0.739 & & & \\
\hline 5 & 0.341 & & & \\
\hline 1 & & 0.601 & & \\
\hline
\end{tabular}




\begin{tabular}{|l|l|l|l|l|}
\hline 2 & & 0.773 & & \\
\hline 3 & & 0.308 & & \\
\hline 4 & & 0.739 & & \\
\hline 1 & & & 0.677 & \\
\hline 2 & & & 0.398 & \\
\hline 3 & & & 0.641 & \\
\hline 4 & & & 0.803 & \\
\hline 5 & & & 0.814 & \\
\hline 6 & & & 0.779 & \\
\hline 7 & & & & 0.743 \\
\hline 1 & & & & 0.684 \\
\hline 2 & & & & 0.480 \\
\hline 3 & & & & 0.462 \\
\hline 4 & & & & 0.353 \\
\hline 5 & & & & 0.640 \\
\hline 6 & & & & 0.618 \\
\hline 7 & & & & \\
\hline 9 & & & & \\
\hline
\end{tabular}

Utilizing the Scree plot, and after identifying the internal consistency of the instrument items, four factors with Eigen Value above 1.04, which explained 57.516\% of the total variance, were identified (Figure 1).

Scree Plot

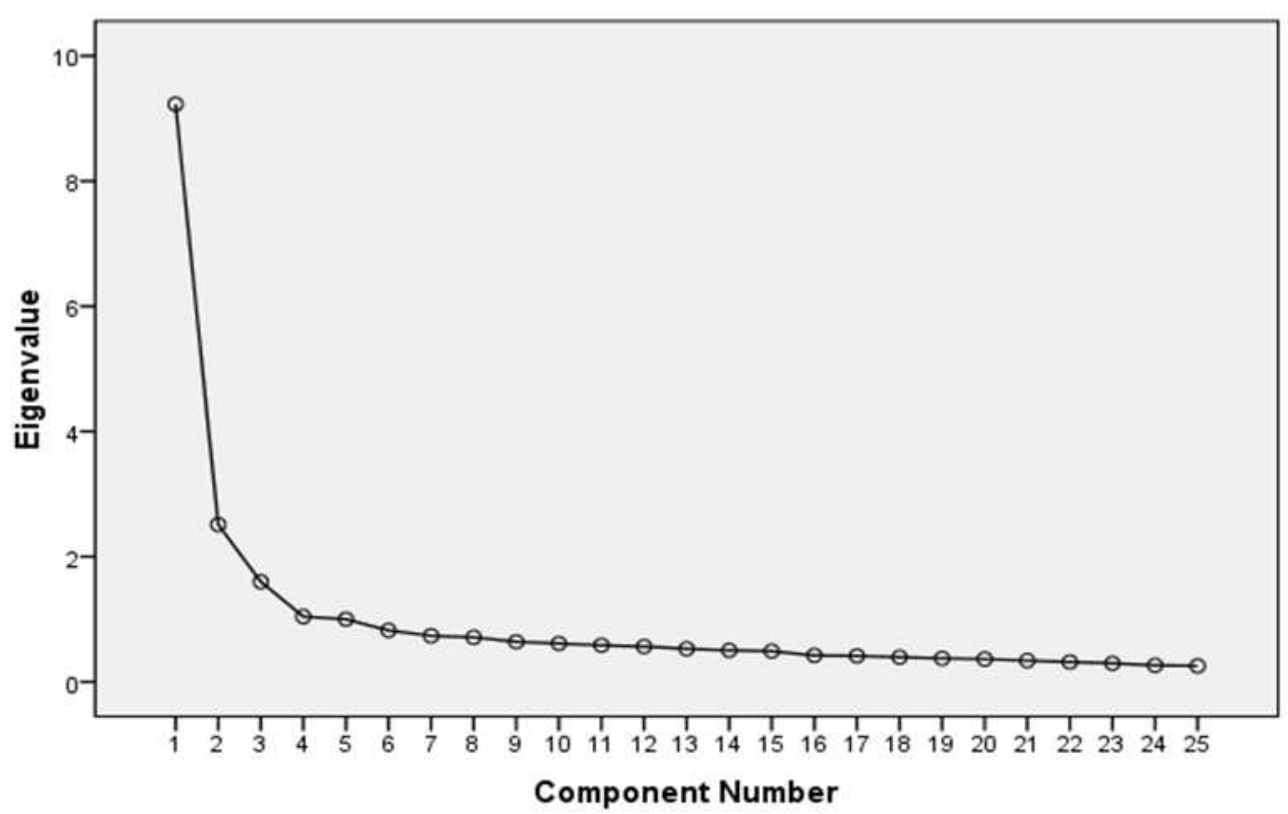

Figure 1) Scree plot for determining factors of the designed instrument

As can be observed in Table 5, the whole questionnaire was loaded in the related domains, and the KMO value for the extractive agent was higher than 0.8 . Also, the percentage of variance 
expressed for the extractive agent was 63.93. Besides, Bartlett's test results confirmed the adequacy of exploratory factor analysis for this extractive factor.

Table 5) Exploratory Factor Analysis Results for the Whole Instrument

\begin{tabular}{|c|c|}
\hline Items & Factor Loading \\
\hline Predisposing & 0.708 \\
\hline Reinforcing & 0.517 \\
\hline Enabling & 0.808 \\
\hline KMO & 0.888 \\
\hline Bartelt P & $<0.001$ \\
\hline Percentage of noted variance & 63.93 \\
\hline
\end{tabular}

In the next step, confirmatory factor analysis was handled to approve the structure of exploratory factor analysis. Due to the values of indicators presented for each of these substructures, as seen in Table 6, the chi $^{2}$ index was less than 5 degrees free, which confirmed the appropriateness of models. Also, GFI, AGFI, NFI, RFI, IFI, and CFI indices more significant than 0.9, RMSEA was less than 0.1, which confirmed this model's validity. As a result, this model has achieved a relatively good level of grace, and due to them, the PRECEDE model factors can be confirmed [37] (Figure 2).

Table 6) Fitting Indicators to Confirm the Suitability of the Model Studied

\begin{tabular}{|c|c|c|c|c|c|c|c|c|c|c|}
\hline $\boldsymbol{\chi 2}^{2}$ & df & $\mathbf{P}$ & $\boldsymbol{\chi 2} / \mathbf{d f}$ & GFI & AGFI & RMSEA (95\% CI) & NFI & RFI & IFI & CFI \\
\hline 2378.84 & 776 & 0.000 & 3.065 & 0.92 & 0.90 & $0.072(0.069: 0.075)$ & 0.94 & 0.91 & 0.96 & 0.96 \\
\hline
\end{tabular}




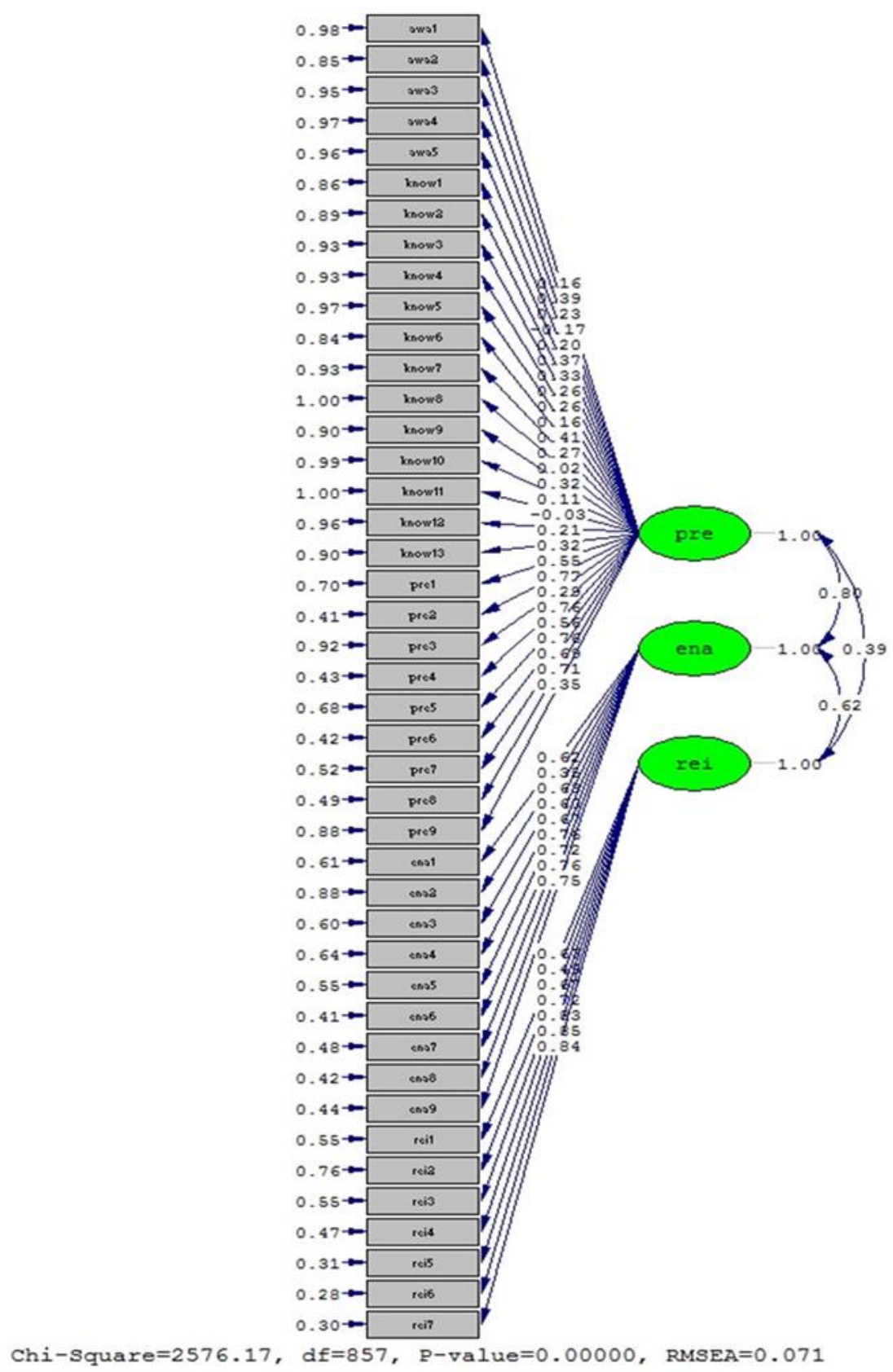

Figure 2) Results from Confirmatory Factor Analysis

\section{Discussion}

Due to the lack of access to comprehensive and suitable scientific tools in evaluating Health workers' skills in obtaining a self-care program for prediabetes, this study was conducted to design and psychometrically evaluate a suitable questionnaire. After a purposeful review of valid texts, a list of items related to the study's aim involving 54 items was developed. In face validity, 15 health workers were enrolled in the study. At this stage, eight items were removed. The items that were deleted at this step were mainly related to laboratory results and complications of diabetes, which due to participants, awareness of these items in obtaining selfcare programs for prediabetes people was less important, so their impact factor score was less than 1.5 (e.g., 1. Which of the following is not the complications of diabetes?; 2. Which of the 
following symptoms are ketoacidosis symptoms?; Or 3. What may be caused by low blood glucose levels?). In the next step, utilizing the opinions of 10 experts, the ratio and validity index of the content of the questionnaire items was calculated, in which three questions were removed due to the lack of necessity in the questionnaire (1. Prediabetics with interest in the training, and this makes me encouraged; 2 . Material encouragement increases my motivation to perform my duties; and 3. Immaterial encouragement increases my motivation to perform my duties). Finally, due to these steps' results, 43 items were approved in three areas of predisposing, enabling, and reinforcing factors.

Evaluation of internal reliability (Cronbach's alpha) between 0.87 and 0.88 for this instrument's structures shows the acceptability of these scales. In other words, these amounts showed that each structure measures the same subject [36]. The prepared questionnaire had acceptable stability due to the results obtained from the Pearson correlation coefficient and the intra-cluster correlation coefficient. This result indicates that this questionnaire can provide reliable results in different temporal and spatial conditions [38]; it should be noted that this study's findings are consistent with the results of some similar research [39-41].

Another significant feature of the questionnaire is validity, which aims to identify a tool's ability to measure what is designed to measure it. The most significant step in identifying the questionnaire's validity is determining the construct's validity, which factor analysis is the best method for this part [42]. Factor analysis is used to identify clusters of related questions of the instrument or scale used. The value of this index between 0.8-0.9 shows optimal factor analysis and more than 0.9 excellent factor analysis. The results of KMO (0.88) and Bartlett test ( $>0.001)$ confirm the factor analysis model and indicate its suitability (33). The results show that the questionnaire is multifactorial (three factors). Since the minimum factor load required for the inclusion of a phrase in a factor depends on the number of instrument expressions and the intended specific value, the cut-out point of 0.3 was considered the minimum factor load required for each expression to maintain it. Considering that the factor load of item 2 of the reinforcing construct was less than 0.3 , therefore, this item can be removed from the questionnaire.

Due to the results of confirmatory factor analysis, it was found that the designed questionnaire has good fitness in Iranian society. Because the fitness statistics had reached an acceptable threshold, similar to the findings of this study, it can be seen in the Bukhsh study that the designed questionnaire had a good quality [43]. Thus, due to the obtained results, the differential validity of defined structures is confirmed.

Many similar research pieces that have designed and standardized the diabetes questionnaire have mainly examined patients' behavior [44-46], and a model-based tool that can examine health workers' skills was not found, so similar researches are handled to compare and better survey this tool.

Due to the limitations caused by the spread of COVID-19, the questionnaire was completed online by participants that the researchers were not aware of the conditions of questionnaire completion and it could have an impact on the answers provided, as well as considering that this study has been done on health workers, so it is not possible to generalize to other care groups such as nurses and physicians. It is suggested that similar studies on other health caregivers be done.

\section{Conclusion}

Health workers' skill evaluation questionnaire was designed to obtain a self-care program for prediabetes due to the PRECEDE-PROCEED model. The above tool is suitable and usable for 15 minutes due to its suitable reliability and validity, easiness and smoothness, and ability to complete. Considering the significance of controlling and preventing chronic diseases, especially type 2 diabetes, and the lack of valid and reliable theory-based tools following the social, cultural, and health conditions of the Iranian community, this research can be beneficial to achieve the above objectives and be applied for similar researches in future. 


\section{Acknowledgments}

We thank the sponsor of the study, National Institute for Medical Research Development (NIMAD) of the Islamic Republic of Iran and Tarbiat Modares University. The authors need to express their gratitude to the experts who helped in different stages with their valuable comments, as well as health-workers of the Mazandaran University of Medical Sciences, which had the maximum cooperation with researchers to carry out this project.

Disclosure of Interes : The authors declare that there is no conflict of interest.

\section{References}

[1] Williams J, Allen L, Wickramasinghe K, Mikkelsen B, Roberts N, Townsend N. A systematic review of associations between non-communicable diseases and socioeconomic status within low-and lower-middle-income countries. Journal of global health. 2018;8(2).

[2] Collaborators GRF. Global, regional, and national comparative risk assessment of 79 behavioural, environmental and occupational, and metabolic risks or clusters of risks in 188 countries, 1990 2013: a systematic analysis for the Global Burden of Disease Study 2013. Lancet (London, England). 2015;386(10010):2287.

[3] International Diabetes Federation. IDF DIABETES ATLAS - 8TH EDITION. from: https://diabetesatlas.org/across-the-globe.html.

[4] Le Boudec J, Marques-Vidal P, Cornuz J, Clair C. Smoking cessation and the incidence of prediabetes and type 2 diabetes: a cohort study. Journal of Diabetes and its Complications. 2016;30(1):43-8.

[5] Qin L, Xu H. A cross-sectional study of the effect of health literacy on diabetes prevention and control among elderly individuals with prediabetes in rural China. BMJ open. 2016;6(5):e011077.

[6] Beulens J, Rutters F, Ryden L, Schnell O, Mellbin L, Hart H, et al. Risk and management of prediabetes. European journal of preventive cardiology. 2019;26(2_suppl):47-54.

[7] Swindell N, Mackintosh K, McNarry M, Stephens JW, Sluik D, Fogelholm M, et al. Objectively measured physical activity and sedentary time are associated with cardiometabolic risk factors in adults with prediabetes: the PREVIEW study. Diabetes care. 2018;41(3):265-9.

[8] Hostalek U. Global epidemiology of prediabetes-present and future perspectives. Clinical diabetes and endocrinology. 2019;5(1):1-5.

[9] Hadaegh F, Derakhshan A, Zafari N, Khalili D, Mirbolouk M, Saadat N, et al. Pre-diabetes tsunami: incidence rates and risk factors of pre-diabetes and its different phenotypes over 9 years of follow-up. Diabetic Medicine. 2017;34(1):69-78.

[10] Wang J, Zhang R-Y, Chen R-P, Sun J, Yang R, Ke X-Y, et al. Prevalence and risk factors for diabetic retinopathy in a high-risk Chinese population. BMC public health. 2013;13(1):633.

[11] Ibrahim N, Moy FM, Awalludin IAN, Ali Z, Ismail IS. The health-related quality of life among pre-diabetics and its association with body mass index and physical activity in a semi-urban community in Malaysia-a cross sectional study. BMC Public Health. 2014;14(1):298.

[12] Hansen S, Huttunen-Lenz M, Sluik D, Brand-Miller J, Drummen M, Fogelholm M, et al. Demographic and social-cognitive factors associated with weight loss in overweight, pre-diabetic participants of the PREVIEW study. International journal of behavioral medicine. 2018;25(6):682-92. 
[13] Feldman AL, Griffin SJ, Ahern AL, Long GH, Weinehall L, Fhärm E, et al. Impact of weight maintenance and loss on diabetes risk and burden: a population-based study in 33,184 participants. BMC Public Health. 2017;17(1):170.

[14] Muraki I, Imamura F, Manson JE, Hu FB, Willett WC, van Dam RM, et al. Fruit consumption and risk of type 2 diabetes: results from three prospective longitudinal cohort studies. Bmj. 2013;347:f5001.

[15] Xi B, Li S, Liu Z, Tian H, Yin X, Huai P, et al. Intake of fruit juice and incidence of type 2 diabetes: a systematic review and meta-analysis. PloS one. 2014;9(3).

[16] Tabák AG, Herder C, Rathmann W, Brunner EJ, Kivimäki M. Prediabetes: a high-risk state for diabetes development. The Lancet. 2012;379(9833):2279-90.

[17] American Association of Diabetes Educators (AADE) .Competencies for Diabetes Educators and Diabetes Paraprofessionals.2016. Available from: https://www.diabeteseducator.org/docs/default-source/practice/practice resources/comp003.pdf.

[18] Somerville M, Ball L, Sierra-Silvestre E, Williams LT. Understanding the knowledge, attitudes and practices of providing and receiving nutrition care for prediabetes: an integrative review. Australian Journal of Primary Health. 2019;25(4):289-302.

[19] Mansoorian MR, KHosrovan S, Sajjadi M, Soltani M, KHazaei A. Effect of Team Member Teaching Design on Knowledge of Health Personnel about Diabetes. Journal of Diabetes Nursing. 2018;6(2).

[20] Mansoorian MR, KHosrovan S, Sajjadi M, Soltani M, KHazaei AJJoDN. Effect of Team Member Teaching Design on Knowledge of Health Personnel about Diabetes. 2018;6(2).

[21] Jamshidi HR, Cook DA. Some thoughts on medical education in the twenty-first century. Medical Teacher. 2003;25(3):229-38.

[22] Silverman J, Krieger J, Sayre G, Nelson K. The value of community health workers in diabetes management in low-income populations: a qualitative study. Journal of community health. 2018;43(5):842-7.

[23] Hill J, Peer N, Oldenburg B, Kengne AP. Roles, responsibilities and characteristics of lay community health workers involved in diabetes prevention programmes: a systematic review. PloS one. 2017;12(12):e0189069.

[24] Javanparast S, Windle A, Freeman T, Baum F. Community health worker programs to improve healthcare access and equity: are they only relevant to low-and middle-income countries? International Journal of Health Policy and Management. 2018;7(10):943.

[25] Nikniaz Z, Jafarabadi MA, Ghaffarifar S, Saeedi Z, Namvar ZA, Shirmohammadi M. Psychometric properties of the Persian version of the celiac disease adherence test questionnaire. BMC gastroenterology. 2020;20(1):1-6.

[26] Nahidi F, Tavafian SS, Heidarzadeh M, Hajizadeh E, Montazeri A. The Mother-Newborn Skinto-Skin Contact Questionnaire (MSSCQ): development and psychometric evaluation among Iranian midwives. BMC pregnancy and childbirth. 2014;14(1):85.

[27] Lawshe C. A quantitative approach to content validity. Pers Psychol. 1975;28(4):563-75.

[28] Tavousi M, Haeri-Mehrizi A, Rakhshani F, Rafiefar S, Soleymanian A, Sarbandi F, et al. Development and validation of a short and easy-to-use instrument for measuring health literacy: the Health Literacy Instrument for Adults (HELIA). BMC Public Health. 2020;20:1-11.

[29] Kharazi S, Peyman N, Esmaily H. An evaluation of the validity and reliability of the maternal health literacy and pregnancy outcome questionnaire. J Health Syst Res. 2016;12(4):512-9. 
[30] Cronbach LJ, Meehl PE. Construct validity in psychological tests. Psychological bulletin. 1955;52(4):281.

[31] Kline RB. Principles and practice of structural equation modeling, 3th ed. Guilford Press, NewYork. 2010.

[32] Ainur A, Sayang M, Jannoo Z, Yap B. Sample Size and Non-Normality Effects on Goodness of Fit Measures in Structural Equation Models. Pertanika Journal of Science \& Technology. $2017 ; 25(2)$.

[33] Orcan F. Exploratory and confirmatory factor analysis: which one to use first. Journal of Measurement and Evaluation in Education and Psychology. 2018;9(4):414-21.

[34] Sadat Z, Ghofranipour F, Azin SA, Montazeri A, Goshtasebi A, Bagheri A, et al. Development and psychometric evaluation of the sexual knowledge and attitudes scale for premarital couples (SKAS-PC): An exploratory mixed method study. International Journal of Reproductive BioMedicine. 2018;16(1):41.

[35] Okado I, Cassel K, Pagano I, Holcombe RF. Development and psychometric evaluation of a questionnaire to measure cancer patients' perception of care coordination. BMC health services research. 2020;20(1):52.

[36] Taber KS. The use of Cronbach's alpha when developing and reporting research instruments in science education. Research in Science Education. 2018;48(6):1273-96.

[37] Xu C, Yin M, Mo W. Correlation and differences in lumbopelvic sagittal alignment parameters between lumbar radiographs and magnetic resonance images. Global Spine Journal. 2020:2192568220947049.

[38] Bobak CA, Barr PJ, O’Malley AJ. Estimation of an inter-rater intra-class correlation coefficient that overcomes common assumption violations in the assessment of health measurement scales. BMC medical research methodology. 2018;18(1):93.

[39] Bazvand Z, Tavafian SS, Boozari S, Shahrbanian S. Development and Psychometric of a Questionnaire about Knowledge, Attitude and Practice of Nurses towards Neck Pain Prevention. 2 Journal of Nursing Education. 2020;9(1):1-10.

[40] Kazemi SS, Tavafian S-S, Hidarnia A, Montazeri A. Development and validation of the Occupational Back Pain Prevention Behaviors Questionnaire in nursing personnel. 2019.

[41] Meng R, Li J, Wang Z, Zhang D, Liu B, Luo Y, et al. The Chinese version of the Perceived Stress Questionnaire: development and validation amongst medical students and workers. Health and quality of life outcomes. 2020;18(1):1-17.

[42] Abbas Ebadi, Ziba Taghizadeh, Ali Montazeri, Zahra Shahvari, Mahmoud Tavousi, Razieh Bagherzadeh. Translation, development and psychometric properties of health related measuresPart 2: construct validity, reliability and responsiveness. Health Monitor Journal of the Iranian Institute for Health Sciences Research. 2017;16(4):445-55.

[43] Bukhsh A, Lee SWH, Pusparajah P, Schmitt A, Khan TM. Psychometric properties of the diabetes self-management questionnaire (DSMQ) in Urdu. Health and quality of life outcomes. 2017;15(1):200.

[44] RobatSarpooshi D, Taghipour A, Mahdizadeh M, Azadeh S, AliReza J, Peyman N. Design and psychometric evaluation of self-care behavior assessment tool in diabetic patients. Journal of Diabetes \& Metabolic Disorders. 2020:1-8.

[45] Stühmann LM, Paprott R, Heidemann C, Ziese T, Hansen S, Zahn D, et al. Psychometric properties of a nationwide survey for adults with and without diabetes: the "disease knowledge and information needs-diabetes mellitus (2017)" survey. BMC public health. 2020;20(1):192. 
[46] Lee E-H, Lee YW, Lee K-W, Nam M, Kim SH. A new comprehensive diabetes health literacy scale: Development and psychometric evaluation. International journal of nursing studies. 2018;88:1-8. 
Figures

\section{Scree Plot}

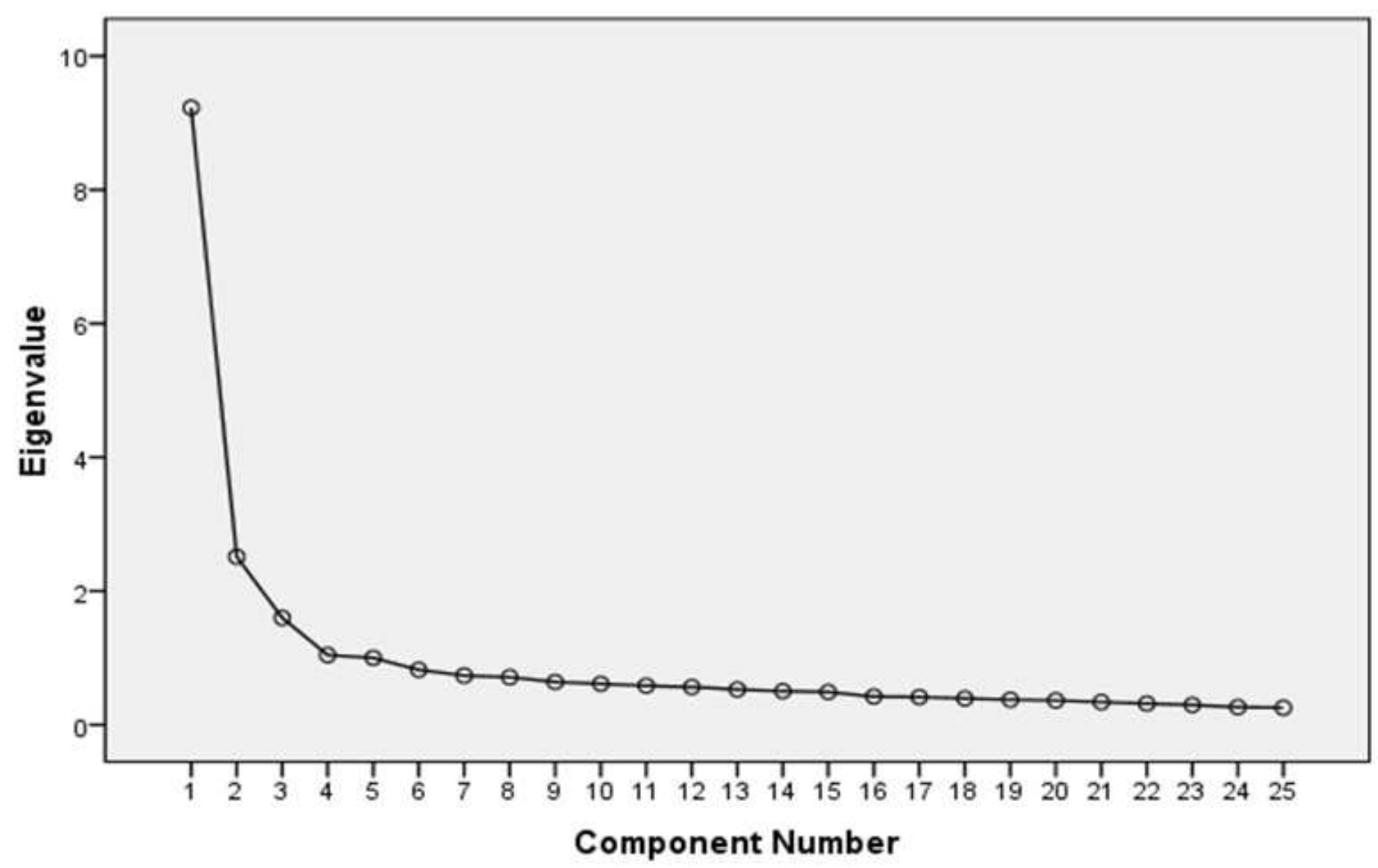

Figure 1

Scree plot for determining factors of the designed instrument 


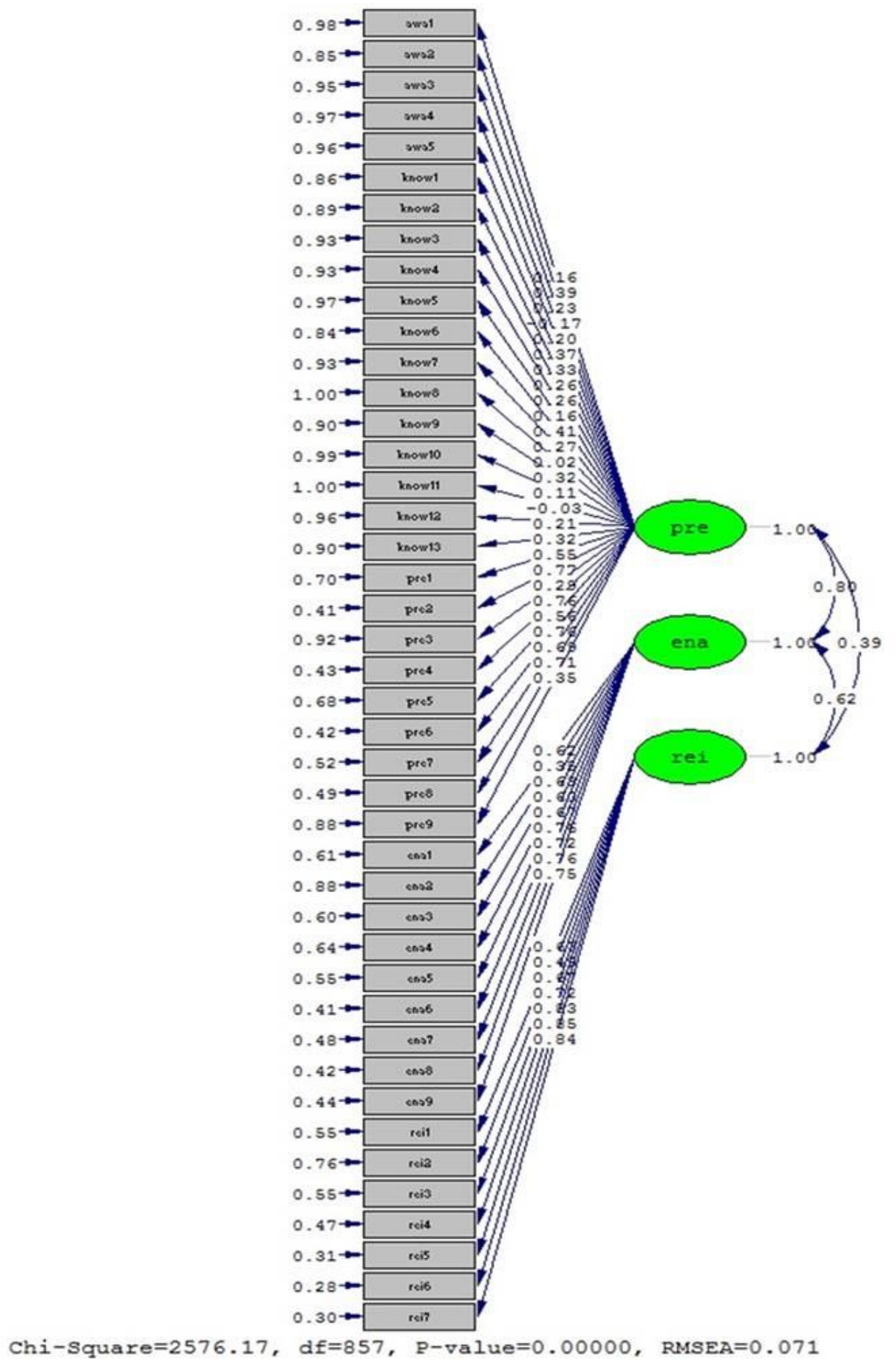

\section{Figure 2}

Results from Confirmatory Factor Analysis 